3

\title{
MODERNIDAD, SECULARIZACIÓN Y REPRESENTACIÓN TRÁGICA EN KARL MARX
}

Juan Pablo Giordano

el_giord@yahoo.com.ar / Profesor en Historia (Universidad Nacional del Litoral). Ayudante de cátedra en la asignatura Análisis del Discurso Historiográfico (Facultad de Humanidades y Ciencias-UNL). Miembro del Centro de Estudios de los Discursos Sociales (CEDiS) y miembro del Comité de Redacción de la revista De Signos y Sentidos (ambos radicados en FHuC-UNL). Cursa la Maestría de Ciencias Sociales (FCJS-FHuC/UNL). 


\section{RESUMEN}

En este artículo nos interesa relevar las maneras en que Karl Marx trata el sentido de las representaciones en (y las representaciones del sentido de) la sociedad moderna, y cómo éstas se relacionan con sus procedimientos de análisis y marcos conceptuales. En Marx subyace una perspectiva teórica informada por la tragedia como género poético y teatral, que subraya la naturaleza escindida y agonal del lazo social, y sus aportes representan al lazo social como forjado en una factura (tendencialmente) trágica. Observamos una atención por los desplazamientos del sentido social sobre un eje que va de lo sagrado a lo profano, y a través de éste, el modo en que Marx asume el análisis de aquellas representaciones que sacralizan el lazo social.

\section{ABSTRACT}

In this article, we approach the ways that Karl Marx deals with the meaning of representations in (and sense representations about) modern society, and how they relate to his analysis methods and conceptual frameworks. A theoretical perspective informed by tragedy as poetic and theatrical genre lies in Marx, underscoring the split and agonistic nature of social bond. His contributions represent the social bond forged by a (tendentiously) tragic bill. We observe how Marx analyzes the displacements of sense on an axis which runs from the sacred to the profane, and also his analysis about representations through wich social bond becomes sacred.

\section{PALABRAS CLAVE}

$>$ modernidad

$>$ secularización

$>$ representación trágica

> sacralización del lazo social

\section{KEY WORDS}

$>$ modernity

$>$ secularization

$>$ tragic representation

> social bond sacralization 
1.

La pregunta por la condición moderna es inherente a la conformación de la teoría social clásica. Y no es para menos, dado que la Modernidad en tanto época ofrece por primera vez en la historia mundial una profusa capacidad semántica para autodescribirse con relación al tiempo y al espacio, operando así una redistribución de otras épocas y zonas, ahora determinadas por referencia a una dimensión temporal (tendencialmente) unitaria y a un cosmos que es tanto geográfico como conceptual: Occidente. Modo de nombrar un proyecto global en el que, in nuce, coinciden dos formas de conocimiento: el geográfico (la expansión ultramarina europea a fines del siglo XV por un globo terráqueo, hallando cabal representación en la cartografía que nos remite a la idea de una esfera total, navegada y ya conocida, a la finitud planetaria del proceso en ciernes) y el filosófico (por el cual el mundo se expande como sentido - y el sentido se estructura como mundo-, subvirtiendo la división entre lo externo y lo interno, y su posibilidad concomitante de relación con "otros" mundos, dimensiones o formas de vida) (cf. Marramao, 2006:15-17).

De esta manera, y como surge de lo antedicho, hallamos vinculada a la Modernidad (amén de sus dimensiones espacio-temporales peculiares) con problemáticas de representación y de sentido que se construyen con cada observación que intenta definirla. Vale decir: la Modernidad se nos presenta tanto como una ontología (una época caracterizada por el desarrollo capitalista industrial, el despliegue de instituciones de control - tales como los Estados burocráticos y las fuerzas armadas - y de los medios masivos de comunicación, todos ellos apoyados en señales simbólicas y sistemas expertos que desanclan las relaciones copresenciales; cf. Giddens, 1993) cuanto como una epistemología (la Modernidad como oferta de sentido, de distinciones plurales que permiten elaborar diferentes descripciones, referidas y apoyadas en el descubrimiento de la perspectiva o punto de vista, aporte capital que brindó el Renacimiento).

Distinciones, descripciones, puntos de vista: en la Modernidad, el conocimiento se torna objeto privilegiado del conocimiento. Y la sociología, una forma de conocer la "vertiginosa experiencia vital" de la Modernidad entre otras, embarcada en la dialéctica entre modernización y modernismo, entre el avance científico- 
tecnológico-burocrático y la pregunta por la condición humana en este proceso (Berman, 2011:1-2), asumirá la tarea de interpretar la transición de un orden "comunitario" o "tradicional" a un orden social, ofreciendo representaciones para fundar su perspectiva y explicar las consecuencias de esta transformación. ${ }^{1}$

En el marco de este artículo, nos interesa relevar las maneras en que Karl Marx trata el sentido de las representaciones en (y las representaciones del sentido de) la sociedad moderna, ${ }^{2}$ y cómo éstas se relacionan a sus procedimientos de análisis y marcos conceptuales. Si la "factura del lazo social" es (también, mas no exclusivamente) un problema de sentido, justo es que nos detengamos en aquellos "hechos sociales" 3 que fungen como realizaciones $u$ objetivaciones portadoras de un sentido vinculante para diferentes agentes en diferentes esferas de acción. En nuestra indagación, consideramos que estos problemas y objetos a un nivel tan específico encontró tratamientos laterales en la obra de este autor, por lo que renunciaremos a imponerles una coherencia a priori, y avanzaremos relevando estas cuestiones en forma fragmentaria y exploratoria, convencidos de que, en su andadura intelectual, Marx (antes que una búsqueda metódica y exhaustiva dirigida a estos tópicos) fue "tropezando" con dichos temas (y nosotros con él).

1 Tal es el espíritu "representacional" y "perspectivista" que podemos inferir de las interrogaciones que se (y nos) formuló Max Weber: "Cuando un hijo de la moderna civilización europea se dispone a investigar un problema cualquiera de la historia universal, es inevitable y lógico que se lo plantee desde el siguiente punto de vista: ¿qué serie de circunstancias han determinado que precisamente sólo en Occidente hayan nacido ciertos fenómenos culturales, que (al menos, tal como solemos representárnoslos) parecen marcar una dirección evolutiva de universal alcance y validez?" (1979a:5, cursivas nuestras)

${ }^{2}$ Y especialmente, si fuera posible hallarlos, bajo la forma de diversos usos del lenguaje y la palabra. Deliberadamente nos moveremos en esta imprecisión conceptual, para no forzar la interpretación de los textos con marcos por completo ajenos a sus intenciones y sus maneras de hacer. Sin embargo, no podemos dejar de interpelar a los clásicos de la teoría social con nuestras propias preguntas, surgidas de nuestra área de trabajo específica, a horcajas entre la Historia Intelectual y el Análisis del Discurso Historiográfico.

3 En el sentido dado por Émile Durkheim, entendemos a las representaciones de la sociedad como pertenecientes a "un orden de hechos que presentan características muy especiales: consisten en modos de actuar, de pensar y de sentir, exteriores al individuo, y están dotados de un poder de coacción en virtud del cual se imponen sobre él" (1997:40-41). Justamente, entre estos hechos sociales incluye "el sistema de signos que utilizo para expresar mi pensamiento" (39), y además señala que "no estoy obligado a hablar francés con mis compatriotas (...) pero es imposible no hacerlo" (40). 
Sin embargo, no carecemos de orientaciones previas al respecto. Pierre Bourdieu (1999) nos ha brindado un balance sobre el rol del simbolismo en las teorías sociales clásicas, en el cual hallamos a Marx entre los teóricos que conciben a las producciones simbólicas como instrumentos de dominación. Al concentrarnos en la factura simbólica del lazo social en Marx, recogemos la impronta de la lectura bourdesiana recordando que, en el espacio social, toda relación de fuerza es también, de modo inescindible, una relación de sentido. Como corolario, en dicho autor subyace una perspectiva teórica informada por la tragedia ${ }^{4}$ como género poético y teatral, ${ }^{5}$ que subraya la naturaleza escindida y agonal del lazo social, y esta acogida del conflicto en un marco de inteligibilidad estético nos permite pensar que (si se nos permite la expresión) sus aportes representan al lazo social como forjado en una factura (tendencialmente) trágica.

\section{2.}

Para iniciar este recorrido, proponemos un cotejo de citas, a modo de "juegos de espejo", con otro teórico reputado por Bourdieu (1999) que concibe las producciones simbólicas como instrumentos de dominación: Max Weber. Ello nos servirá para catalizar nuestro argumento. Recordemos algunos pasajes en donde nuestros autores explicitan, ya sea por forma o contenido, nociones

\footnotetext{
${ }^{4}$ En el sentido esbozado por Eduardo Rinesi: "la tragedia es un modo de estilizar o estetizar una historia signada por la centralidad de un cierto conflicto (de un conflicto entre valores o sistemas de valores o dioses enfrentados, sea que lo estén, como en la tragedia antigua, en el mundo objetivo en el que habitan esos dioses, sea porque lo estén, como en la moderna, en el corazón atormentado de un sujeto)" (2013:9-10); "la tragedia tematiza siempre una situación en que los dioses se imponen sobre los hombres, los castigan o los doblegan, o en todo caso muestran su tremenda superioridad y su poder omnímodo sobre ellos. Y si aquí la palabra 'dioses' sonara algo excesiva, o anacrónica, podríamos traducir esta frase que acabo de estampar diciendo que la tragedia tematiza una situación en la que los muertos se imponen sobre los vivos, los viejos sobre los jóvenes, los padres sobre los hijos, o incluso, más en general, en que los hombres descubren su extraordinaria inferioridad respecto a fuerzas (la Providencia, el Destino, el Acaso, lo Contingente, el conjunto de factores sobre los que nos somos soberanos) que no puede predecir ni controlar ni desobedecer, y que terminan imponiéndose sobre él de modo fatal, inexorable y definitivo" (2013:12-13). ${ }^{5}$ Sobre los intereses literarios de Marx en torno a la tragedia antigua y moderna (especialmente, de las obras de Esquilo y Shakespeare), cf. Sazbón (2002) y Vedda (2013).
} 
que vinculan su hacer teórico con una perspectiva trágica. Demás está decir que en la cita al pie de Rinesi hallamos ciertas resonancias: el "enfrentamiento entre dioses" recuerda el politeísmo que Weber postula para tematizar la diferenciación de esferas de valor ${ }^{6}$, y la "imposición de los muertos sobre los vivos" a las expresiones que Marx utiliza para reflexionar sobre las aporías de la acción colectiva histórica:

Los diversos órdenes de valores universales están enfrentados en lucha despiadada. El viejo Mill (...) dijo que si se parte de la pura experiencia se llega al politeismo. (...) dioses diferentes luchan entre sí y, sin duda, ha sido así en todas las épocas. (...) Los múltiples dioses antiguos, despojados de su hechizo, y por tanto, bajo la forma de fuerzas impersonales, salen de sus tumbas, aspiran a dominar nuestras vidas y comienzan de nuevo su eterna lucha. (Weber, 1980:50-52)

Los hombres hacen su propia historia, pero no la hacen a su libre arbitrio, bajo circunstancias elegidas por ellos mismos, sino bajo aquellas circunstancias con que se encuentran directamente, que existen y les han sido legadas por el pasado. La tradición de todas las generaciones muertas oprime como una pesadilla el cerebro de los vivos. (Marx, 2014:103)

\footnotetext{
${ }^{6}$ Recordemos que, para Weber, existe un proceso de intelectualización y racionalización occidental, el cual implica una racionalización de la vida social, caracterizada por una separación creciente entre diferentes esferas de valor (política, económica, estética, erótica, intelectual) entre las cuales prevalece la ciencia como forma de conocimiento paradigmática para el resto de las esferas (Weber, 1998:527-562). La preeminencia de la ciencia está basada en su capacidad para ampliar el saber empírico (susceptible de comprobación), para predecir fenómenos y para desarrollar instrumentos y organizaciones sobre procesos empíricos. De aquí que la expansión de una racionalidad instrumental en los diversos órdenes sociales descanse en dos premisas surgidas en dos momentos del proceso social occidental (Grecia clásica y Renacimiento): a) la posibilidad de entender el mundo por conceptos, es decir, que el mundo es susceptible de ser comprendido echando mano al despliegue de un universo conceptual anclado en los rigurosos moldes de la lógica; y b) la experimentación racional rigurosamente controlada y la elevación del experimento como fundamento de la ciencia empírica (Weber, 1980: 40-41). Es por esto que Weber observa una creciente intelectualización que desencanta o "desmagifica" al mundo, en base a la presencia del cálculo en todos los órdenes de la vida social. El cálculo funge como modelo pasible de generalización, aplicable a la interpretación de toda acción en todo tiempo y lugar. De esta manera, el parámetro ideal de racionalidad con el que se comprende y evalúa una acción social es la adecuación entre medios y fines.
} 
Del cotejo de citas podemos inferir un par de reenvíos cruzados altamente significativos a nuestro propósito. En primer lugar, podemos afirmar, en palabras de Weber, que éste comparte "la conciencia de la urdimbre trágica en que se asienta la trama de todo quehacer humano y especialmente del quehacer político" (1979b:156), como la que involucra el análisis de la lucha de clases en Francia por Marx:

Es una tremenda verdad y un hecho básico de la historia (...) el que frecuentemente, o mejor generalmente, el resultado final de la acción política guarda una relación absolutamente inadecuada, y frecuentemente incluso paradójica, con su sentido originario. Esto no permite, sin embargo, prescindir de ese sentido, del servicio a una 'causa', si se quiere que la acción tenga una consistencia interna (Weber, 1979b:156).

En segundo lugar, la pervivencia de la tradición de las generaciones pasadas, y su influjo efectivo en el presente que Marx destaca, parece cuajar superficialmente con la idea weberiana del "retorno de los antiguos dioses" (máxime si tenemos en cuenta que ambos contextualizan sus apreciaciones en momentos críticos y/o revolucionarios de la sociedad moderna). Sin embargo, se introduce una nota de discordancia: allí donde Weber percibe este retorno "bajo formas impersonales", "despojados de hechizo", Marx advierte que el regreso de las tradiciones ("esas conjuraciones de los muertos en la historia universal"; 2014:104) puede suceder bajo formas "hechizadas" o, digamos para contrastar un célebre dictum weberiano, "re-encantadas":

Y cuando estos [los vivos] aparentan dedicarse precisamente a transformarse y a transformar las cosas, a crear algo nunca visto, en estas épocas de crisis revolucionarias es precisamente cuando conjuran temerosos en su auxilio los espíritus del pasado, toman prestados sus nombres, sus consignas de guerra, su ropaje, para, con este disfraz de vejez venerable y este lenguaje prestado, representar la nueva escena de la historia universal. (Marx, 2014:103)

Lo que diferenciaría una "representación de escena" farsesca de una trágica no sería la mera conjuración de espíritus pasados: Marx constata que tanto la Re- 
volución Inglesa del siglo XVII cuanto la Francesa de 1789 asumieron los "ropajes" del Antiguo Testamento y de la República e Imperio Romano, respectivamente. La escena deviene farsa7 cuando la "veneración supersticiosa del pasado" (2014: 106) impide extraer la "poesía del porvenir" (2014:105) que torne inteligible las tareas históricas correspondientes a las revoluciones sociales del siglo XIX:

En esas revoluciones [la inglesa del siglo XVII y la francesa de 1789], la resurrección de los muertos servía, pues, para glorificar las nuevas luchas y no para parodiar las antiguas, para exagerar en la fantasía la misión trazada y no para retroceder ante su cumplimiento en la realidad, para encontrar de nuevo el espíritu de la revolución y no para hacer vagar otra vez su espectro. (Marx, 2014:104-105)

\footnotetext{
${ }^{7}$ Y los actores principales devienen farsantes conspicuos, o más bien, la escena farsesca (los "enredos" y "equívocos" que impiden a una clase o conjunto de clases encarnar la hegemonía en una sociedad determinada) favorece cierto ethos político que sepa jugar con las apariencias: la mascarilla mortuoria y el manto de Napoleón utilizados hábilmente por el comediante de su sobrino Luis (embustero, chantajista, brujo, prestidigitador... Marx no ahorra epítetos para quien puede engañar mediante trucos y hechizos): "Viejo roué [libertino] ladino, concibe la vida histórica de los pueblos y de los grandes actos de gobierno y de Estado como una comedia, en el sentido más vulgar de la palabra, comoo una mascarada, en que los grandes disfraces y las frases y gestos no son más que la careta para ocultar lo más mezquino y miserable" (Marx, 2014:151, cursivas nuestras). Llama notablemente la atención que Weber coincida en señalar (y criticar) esta tendencia subyacente a los liderazgos políticos demagógicos: el peligro "tanto de convertirse en un comediante como de tomar a la ligera la responsabilidad que por las consecuencias de sus actos le incumbe y preocuparse sólo por la 'impresión' que hace. Su ausencia de finalidad objetiva le hace proclive a buscar la apariencia brillante del poder en lugar del poder real; su falta de responsabilidad lo lleva a gozar del poder por el poder, sin tomar en cuenta su finalidad" (1979b:155, cursivas nuestras). Bien pensado, no llama tanto la atención: Marx y Weber observan (uno in status nascendi, el otro en su despliegue y consolidación) la construcción de liderazgos políticos carismáticos, sustentados en apoyos plebiscitarios de bases masivas vinculadas emotivamente a su caudillo, forjados mediante máquinas partidarias que captan votos y fondos dispensando prebendas y beneficios (materiales y simbólicos) entre sus seguidores (cf. Weber, 1979b). [Una digresión: la lectura de Marx del proceso francés entre 1848 y 1852 ha gozado de largo alcance heurístico, al formular una imagen potente de lo que, con posterioridad, se denominaría bonapartismo: la resolución de una crisis orgánica a través de la asociación entre liderazgos carismáticos movilizadores y manejo (o velamiento o distorsión) de apariencias políticas y sociales. Baste recordar un ejemplo local: el historiador trotskista Milcíades Peña (y marxista trágico, según su biógrafo Horacio Tarcus) caracterizó el bonapartismo del primer gobierno peronista a través de un título por demás sugerente: El gobierno del "como si".]
} 
Leímos bien: para encontrar de nuevo el espíritu de la revolución. Este "espíritu" glorifica luchas nuevas, glorifica la novedad de las luchas, fomenta la fantasía que permite cumplir misiones asignadas en la realidad, que permite avanzar por la dirección que trazan estas misiones. Pero, ies que acaso existan otros "espíritus" tan sublimes que haya que encontrar de nuevo?:

Los elementos esenciales de esa mentalidad que llamamos 'espíritu del capitalismo', son justamente los mismos que acabamos de reconocer como contenidos de la ascesis profesional puritana (...). El puritano quiso ser un hombre profesional, nosotros tenemos que serlo también, pues desde el momento en que el ascetismo abandonó las celdas monásticas para instalarse en la vida profesional y dominar la eticidad intramundana, contribuyó en lo que pudo a construir el grandioso cosmos de orden económico moderno que, vinculado a las condiciones técnicas y económicas de la producción mecánico-maquinista, determina hoy con fuerza irresistible el estilo vital de cuantos individuos nacen en él (no sólo de los que en él participan activamente), y de seguro lo seguirá determinando durante muchísimo tiempo más. (Weber, 2003:285-286, cursivas nuestras)

Lo sublime del "espíritu del capitalismo" también discurre por imágenes que inflaman las fantasías de las tareas y la dirección hacia donde avanzó y debe avanzar la ascesis profesional: la construcción de un cosmos u orden económico "grandioso", que determina y seguirá determinando "durante muchísimo tiempo", "con fuerza irresistible", la experiencia vital de infinidad de individuos. ${ }^{8}$ El "espíritu del capitalismo", encarnado en el poder creciente e irresistible de las riquezas de este mundo sobre los hombres (Weber: 2003:286), se Manifiesta de forma francamente hechizante:

\footnotetext{
8 "La perspectiva cósmica y la grandeza visionaria de esta imagen, su fuerza dramática altamente concentrada, su tono vagamente apocalíptico, la ambigüedad de su punto de vista (...), todas estas cualidades son supuestamente el sello distintivo de la imaginación modernista" (Berman, 2011:83). Notemos, de paso, que Berman se refiere en estos términos no a Weber sino a Marx.
} 
Las relaciones burguesas de producción y de cambio, las relaciones burguesas de propiedad, toda esta sociedad burguesa moderna, que ha hecho surgir como por encanto tan potentes medios de producción y de cambio, se asemeja al mago que ya no es capaz de dominar las potencias infernales que ha desencadenado con sus conjuros. (Marx, 2014:74, cursivas nuestras)

Ahora, un fantasma recorre la modernidad burguesa: "la idea del 'deber profesional' ronda por nuestra vida como un fantasma de ideas religiosas ya pasadas" (Weber, 2003:286-287, cursivas nuestras).

Hasta aquí, encontramos algunos elementos coincidentes o afinidades electivas en ambas perspectivas: a saber, ambos dan cuenta del peso de los legados de sentido de las generaciones pasadas (tradiciones) y sus modos de acción y comprensión en el orden social actual, ya sea por la ascesis intramundana como conducción de vida, que ha brindado un ética contribuyente al desarrollo material del capitalismo, perdiendo en este tránsito su sentido religioso original (Weber); ya sea por la semántica de las revoluciones pasadas de las que se apropian la acción política y la lucha social (bueno es recordarlo, anti-capitalista) presente, para justificar, elevar y/o glorificar sus tareas actuales (Marx).

Si se pudiera formular de otro modo: en ambos teóricos observamos una atención por los desplazamientos del sentido social sobre un eje que va de la forma al contenido, de la transparencia a la opacidad, de lo material a lo ideal, o si se quiere, de lo sagrado a lo profano. Nos detenemos en este último par conceptual porque, siguiendo a Giacomo Marramao (1998) podemos, desde su trabajo sobre el concepto de secularización, interpretar no sólo el sentido atribuido a los procesos sociales propios de la Modernidad, sino también comprender cómo se conforma la observación de estos procesos: un punto de vista que es él mismo moderno, dado que renuncia al lugar del metaobservador y sabe que todas sus afirmaciones sobre la sociedad moderna dependen de la sociedad moderna para ser formuladas. Así, la representación de la sociedad "es un problema que sólo se puede formular en la sociedad y sobre el que sólo en la sociedad se puede decidir en una u otra manera" (Luhmann, 1997:122).

Decíamos, pues, secularización. Porque con tal concepto se señala, generalmente, el proceso de separación entre las esferas políticas y religiosas, lo cual "habría contribuido para hacer al poder temporal consciente de su propia 
autonomía, es decir, de la irreductible 'secularidad' de la política y de los fundamentos intramundanos (...) de la soberanía estatal" (Marramao, 1998:25). Esto también comportaría un sentido anexo: el hecho de que las doctrinas y las representaciones religiosas comienzan a mostrarse insuficientes para explicar el mundo y proveerlo de un sentido global, omnicomprensivo, frente a otros modos de observación (otras distinciones) que empiezan a trazarse en ámbitos intramundanos, ajenos a y separados de las instituciones religiosas. Pero también la secularización se puede entender de un modo paradójico y no-teleológico: lo sagrado abandona el "cielo" de las concepciones religiosas y se desplaza hacia otros ámbitos "de esta tierra", propiciando un intercambio simbólico o "juego de espejos" en el que otras esferas sociales (comenzando por el Estado) asumen prerrogativas eclesiásticas en torno a sacralizar sus propios procedimientos (26).

Mucho de estas concepciones emerge de las observaciones trazadas por Marx y Weber. En ambos encontramos una recurrencia a la racionalidad para explicar la transformación de la Modernidad: básicamente, que la transición de un orden tradicional a la sociedad moderna comporta una lógica y una dinámica aprehensible mediante el ejercicio sistemático de la reflexión, con herramientas conceptuales elaboradas en el devenir de su misma conformación, para lo cual no es tarea menor la crítica y el abandono de las concepciones religiosas heredadas. Podríamos formularlo en los términos arriba mencionados: los procesos materiales de la modernidad son la condición de la transparencia de su inteligibilidad, del desvelamiento de su lógica inherente ${ }^{9}$. Pero asimismo, de este mismo proceso emergen componentes irracionales que sin embargo también ligan las relaciones recíprocas entre los hombres, y que arrojan velos sobre una mirada sociológica que no puede menos que contemplar, frecuen-

\footnotetext{
${ }^{9}$ En este tenor juzgamos ejemplares las expresiones de Marx y Engels vertidas en el Manifiesto Comunista: "Una revolución continua en la producción (...) distinguen la época burguesa de todas las anteriores. Todas las relaciones estancadas y enmohecidas, con su cortejo de creencias y de ideas veneradas durante siglos, quedan rotas; las nuevas se hacen añejas antes de osificarse. Todo lo estamental y estancado se esfuma; todo lo sagrado es profanado, y los hombres, al fin, se ven forzados a considerar serenamente sus condiciones de existencia y sus relaciones recíprocas" (en Marx, 2014:72, cursivas nuestras).
} 
temente, al orden social como un espectáculo fantasmagórico situado en un escenario material por el que vagan diversos espectros ideales. ${ }^{10}$

Habría que formularse, entonces, algunas preguntas orientadoras: ¿de qué modo asume Marx, en su universo conceptual, los desplazamientos entre lo sagrado y lo profano del proceso secularizador? ¿Cómo analiza la producción de aquellas representaciones o idealizaciones que sacralizan el lazo social (o algunos de sus componentes)? ¿Y cuáles son, por implicación, el perfil y las tareas que asigna a aquellos productores de representaciones privilegiados de la Modernidad: los intelectuales?

Aquí nos interesa retomar algunos hilos argumentales que pergeñamos más arriba. Decíamos que la concepción marxista del lazo social era de factura trágica, incorporando la escisión y el conflicto en su formulación. Ello se debe a que Marx construye sus categorías desde un punto de vista particular: el proletariado, la clase social explotada en el régimen capitalista por la clase dominante propietaria de los medios de producción: la burguesía. Develar científicamente, desmistificar la naturalización de esta relación de explotación implica analizar la forma en que se manifiesta la escisión: el trabajo alienado. En su relación con la naturaleza y con otros hombres, el trabajador produce riqueza con su fuerza de trabajo, pero ésta se objetiva en las mercancías producidas (que son apropiadas por el capitalista, en función de las relaciones de producción imperantes); por ende el obrero se produce a sí mismo como mercancía. Lo trágico del asunto es que no sólo el trabajador se convierte en objeto, sino que el producto de su trabajo se le presenta como un poder exterior e independiente, ya que "la vida que ha prestado al objeto se le enfrenta como cosa extraña y hostil". Digámoslo así: la mercancía se sacraliza: “Lo mismo sucede en la religión. Cuanto más pone

\footnotetext{
10 "La cualidad fetichista que adquiere la mercancía afecta a la misma sociedad productora de mercancías, no ciertamente como ella es en sí, sino tal como continuamente se imagina a sí misma y cree comprenderse cuando abstrae del hecho de que precisamente produce mercancías. La imagen que de este modo produce de ella misma, y la que suele intitular como su cultura, corresponde al concepto de fantasmagoría" (Benjamin, 2009:680).
} 
el hombre en Dios, tanto menos guarda en sí mismo" (Marx, 2001:107). Este "endiosamiento" de lo material halla su prolongación conceptual en el carácter fetichista (místico, enigmático, fantasmagórico) ${ }^{11}$ de la forma mercancía, la forma social por medio de la cual se "refleja ante los hombres el carácter social de su propio trabajo como caracteres objetivos inherentes a los productos de trabajo (...) y, por ende, (...) también refleja la relación social que media entre los productores y el trabajo global, como una relación social entre los objetos, existentes al margen de los productores" (2014:269). Insistimos: en la perspectiva marxista, la materialidad capitalista aparece como radicalmente idealista. Pero, al mismo tiempo, el desarrollo del modo de producción capitalista (en tanto totalidad concreta con múltiples determinaciones y relaciones) despliega un universo conceptual y un método dialéctico con pretensiones de validez universal que lo tornan racional: el "mundo de sentido" capitalista aparece como "mundo de sentido" tout court. ${ }^{12}$

Cabe preguntarse entonces cómo y dónde se gesta una observación dentro de la relación social que pretende desentrañar: para Marx, esta observación lleva el nombre de conciencia. La actividad humana, la praxis, es lo que determina la conciencia, anudando objetivismo y subjetivismo, actividad sensorial y actitud teórica, mediante el trato que entablan los hombres al producir sus medios de existencia, transformando la naturaleza y produciéndose a sí mismos como hombres (Marx y Engels, 1974:11-16). La conciencia es histórica tanto como el modo de producción en el que se despliega: se explica "por las contradicciones de la vida material, por el conflicto entre las fuerzas productivas sociales y las relaciones de producción" y se expresa en "las formas jurídicas, políticas, religiosas, artísticas o filosóficas, en una palabra, las formas ideológicas en que los hombres adquieren conciencia de este conflicto y luchan por resolverlo" (518, cursivas nuestras).

\footnotetext{
11 Todos estos adjetivos son elaborados por Marx mismo para referirse a la mercancía.

12 "La sociedad burguesa es la más compleja y desarrollada organización histórica de la producción. Las categorías que expresan sus condiciones y la comprensión de su organización permiten al mismo tiempo comprender la organización y las relaciones de producción de todas las formas de sociedad pasadas, sobre cuyas ruinas y elementos ella fue edificada y cuyos vestigios, aun no superados, continúa arrastrando, a la vez que meros indicios previos han desarrollado en ella su significación plena, etc." (Marx, 1989:55, cursivas nuestras).
} 
La determinación de las formas ideológicas por el conflicto de clases enmarca la conceptualización del rol de los intelectuales. Por ejemplo, la naturalización del trabajo en la economía clásica vela la mirada del conocimiento científico (aplicado al mundo social) con los intereses de las clases dominantes, encubriendo así las relaciones de explotación. En la perspectiva marxista, "las ideas de la clase dominante son las ideas dominantes en cada época" (45); ello se debe a que, en tanto poder material dominante, dispone también de los "medios de producción espiritual" y de la capacidad de organizar la división del trabajo intelectual, delegando en una parte de su clase - los ideólogos, en un sentido peyorativo- la producción y distribución de ideas. Ahora bien, ¿las clases dominadas tienen intelectuales propios? Marx y Engels mencionan que "la existencia de ideas revolucionarias en una determinada época presupone ya la existencia de una clase revolucionaria" (46), pero ello no comporta (necesariamente) la actividad de un grupo específico, diferente de la propia clase. Incluso Marx denosta a los "teóricos socialistas y comunistas" que "improvisan sistemas" que no se condicen con el desarrollo efectivo del proletariado en lucha y de las fuerzas productivas, conminándolos a convertirse, simplemente, en "portavoces de la realidad". ${ }^{13}$ A lo sumo, según las expectativas plasmadas en el Manifiesto, la polarización creciente del desarrollo capitalista "despojaría de su aureola" (desacralizaría) ${ }^{14}$ a los intelectuales, junto con otros profesionales, arrojándolos a una cruel proletarización de "sirvientes asalariados" (Marx, 2014:71).

Sin embargo, los acontecimientos franceses de 1848 le mostrarían a Marx que la realidad que se desarrollaba ante los ojos no se podía percibir en forma desnuda y descarada; más bien, se (re)presentaba enmascarada, vistiendo ropajes vetustos y hablando un idioma prestado en el que, malamente, la revolución

\footnotetext{
13 "A medida que la historia avanza, y con ella empieza a destacarse con trazos cada vez más claros la lucha del proletariado, aquéllos [los "teóricos socialistas y comunistas"] no tienen ya necesidad de buscar la ciencia en sus cabezas: les basta con darse cuenta de lo que se desarrolla ante sus ojos y convertirse en portavoces de esa realidad" (Marx, 1987:81).

14 "En una palabra: en lugar de la explotación velada por ilusiones religiosas y políticas, [la burguesía] ha establecido una explotación abierta, descarada, directa y brutal" (Marx, 2014:71). Acerca de la dialéctica de la desnudez como metáfora del conocimiento verdadero, formulada por Marx en el Manifiesto Comunista, cf. Berman (2011:102-108)
} 
proletaria traducía las novedades de su hora, ${ }^{15}$ hablando consigo misma y con sus circunstancias en forma directa, ${ }^{16}$ sin intelectuales/traductores. Por ello, "el propio educador necesita[rá] ser educado"17 para forjar un lenguaje de autoconocimiento sensible ${ }^{18}$ que le permita traducir el pasaje de la transparencia a la opacidad, de la desacralización al misterio, inscrito en el jeroglífico social de la mercancía. ${ }^{19}$

4.

Para finalizar, volvemos al principio. Habíamos matizado nuestra calificación de la perspectiva del lazo social en Marx como tendencialmente trágica. Lo mencionamos porque, en sus análisis sobre la sociedad capitalista, Marx esboza un principio trágico, de escisión agonal, constitutivo de dicho orden social: la enajenación del trabajo humano vía explotación económica pura (la compra de fuerza de trabajo por parte de los propietarios de los medios productivos, y la generación de plusvalía) y su "transubstanciación" en mercancía. La contradicción objetiva (no ideal), generada por esta relación entre dos clases antagónicas —burguesía y proletariado-, en ocasiones como las de 1848-1849 adquiere formas trágicas (formas en las que "el contenido desborda la frase": Marx,

15 "Es como el principiante que al aprender un idioma nuevo lo traduce mentalmente a su idioma nativo, pero sólo se asimila el espíritu del nuevo idioma y sólo es capaz de expresarse libremente en él cuando se mueve dentro de él sin reminiscencias y olvida en él su lengua natal" (Marx, 2014:103).

16 "Las revoluciones proletarias, como las del siglo XIX, se critican constantemente a sí mismas (...), se burlan concienzuda y cruelmente de las indecisiones, de los lados flojos y de la mezquindad de sus primeros intentos (...), hasta que se crea una situación que no permite volverse atrás y las circunstancias mismas gritan: Hic Rhodus, hic salta!" (Marx, 2014:106-107, cursivas nuestras).

${ }^{17}$ Marx y Engels (1974:8).

18 "La naturaleza sensible inmediata para el hombre es inmediatamente la sensibilidad humana (...) en la forma del otro hombre sensiblemente presente ante él (...). El elemento del pensar mismo, el elemento de la exteriorización vital del pensamiento, el lenguaje, es naturaleza sensible" (Marx, 2001:149).

19 "El valor (...) no lleva inscrito en la frente lo que es. Por el contrario, transforma a todo producto del trabajo en un jeroglífico social. Más adelante los hombres procuran descifrar el sentido del jeroglífico, desentrañar el misterio de su propio producto social, ya que la determinación de los objetos para el uso como valores es producto social suyo a igual título que el lenguaje" (Marx, 2014:271). 
2014:106) ${ }^{20}$ porque la clase proletaria se halla colocada ante la contradicción entre su debilidad objetiva como movimiento revolucionario y su necesidad histórica de lucha por el poder; así, la tragedia moderna se figura para Marx cuando sus héroes sucumben por haber llegado demasiado temprano a su "cita histórica" (cf. Vedda, 2013:35-37).

Sin embargo, la concepción marxista también abriga una tendencia cómica (en la que los hombres triunfen sobre los dioses, los vivos sobre los muertos y los jóvenes sobre los viejos) en la expectativa de que el conflicto entre fuerzas productivas y relaciones de producción origine el cambio y el movimiento de la historia humana, a través de una dialéctica en la cual el proletariado, surgido de la afirmación del orden capitalista burgués, encarna la contradicción de éste y su virtual negación o superación en un modo de producción que incorpora los adelantos científico-tecnológicos desarrollados por el capitalismo, pero en el cual se supriman la propiedad privada de los medios de producción, base indispensable de la enajenación. La preparación de la clase obrera como clase para sí, mediante su educación en la lucha política, apunta a lograr la coincidencia entre condiciones subjetivas y objetivas para, esta vez, no faltar a la cita revolucionaria: la abolición de toda explotación humana y el inicio de la "verdadera historia humana", la cooperación sin trabas de los productores, la sociedad sin clases.

La convicción de la realización plena de la naturaleza humana en una sociedad sin clases implica, para el marxismo, una mundanización de la teoría social $^{21}$ encarnada en el proletariado y su lucha como sujeto revolucionario. Max Weber siempre se mostró atento en su obra a las implicancias de ciertos procesos propios de la sociedad moderna, algunos de ellos aparentemente ajenos a la naturaleza de la explotación capitalista: la mundanización de las creencias religiosas y las éticas de convicción como modos de conducir y dar sentido a la acción social, la naturaleza de la política como lucha por el poder encarnado en un Estado monopolizador de la violencia, y los procesos concomitantes de dominación carismática y rutinización burocrática en el plexo institucional libe-

\footnotetext{
${ }^{20}$ Sobre los planteos de Marx y Engels acerca de las formas (posibles y mejores) en las que debe representarse la tragedia revolucionaria, cf. Marx y Engels, 2013:199-206.

21 "Los filósofos no han hecho más que interpretar de diversos modos el mundo, pero de lo que se trata es de transformarlo" (Marx y Engels, 1974:10).
} 
ral-democrático de las sociedades europeas. Hacia 1919, en su conferencia sobre La política como vocación, Weber analizaba los acontecimientos revolucionarios suscitados en Rusia desde 1917 (ejecutados en nombre del ideario marxista), así como los intentos de réplica abortados en suelo alemán por la violencia estatal y paraestatal (en momentos en que la caída del derrotado Imperio cedía, a regañadientes, lugar a la República de Weimar), y observaba lo siguiente:

Quien quiera imponer sobre la tierra la justicia absoluta valiéndose del poder necesita para ello seguidores, un "aparato" humano. Para que éste funcione tiene que ponerle ante los ojos los necesarios premios internos y externos. En las condiciones de la moderna lucha de clases, tiene que ofrecer como premio interno la satisfacción del odio y el deseo de revancha y, sobre todo, la satisfacción del resentimiento y de la pasión pseudoética de tener razón (...). Como medios externos tiene que ofrecer la aventura, el triunfo, el botín el poder y las prebendas. (...) En tales condiciones, el resultado objetivo de su acción [del jefe] no está en su mano, sino que le viene impuesto por esos motivos éticos, predominantemente abyectos, de sus seguidores (...). Pero, incluso cuando es subjetivamente sincera, no sólo esta fe [en el jefe y en su causa] no pasa de ser la mayor parte de los casos más que una "legitimación" del ansia de venganza, de poder, de botín y de prebendas (no nos engañemos, la interpretación materialista de la historia no es tampoco un carruaje que se toma y se deja a capricho, y no se detiene ante los autores de la revolución), sino que, sobre todo, tras la revolución emocional, se impone nuevamente la cotidianeidad tradicional: los héroes de la fe y la fe misma desaparecen o, lo que es más eficaz aún, se transforma en parte constitutiva de la fraseología de los pícaros y de los técnicos de la política. Esta evolución se produce de forma especialmente rápida en las contiendas ideológicas porque suelen estar dirigidas o inspiradas por auténticos caudillos, profetas de la revolución. Aquí como en todo aparato sometido a una jefatura, una de las condiciones del éxito es el empobrecimiento espiritual en pro de la "disciplina". El séquito triunfante de un caudillo ideológico suele así transformarse con especial facilidad en un grupo completamente ordinario de prebendados. (Weber, 1979b:171-173, cursivas nuestras)

Para Weber, pactar con los demonios del poder muestra lo trágica que puede terminar resultando la comedia (comunista) en la sociedad moderna. 


\section{REFERENCIAS BIBLIOGRÁFICAS}

Benjamin, W. (2009). Libro de los Pasajes. Madrid: Akal.

Berman, M. (2011). Todo lo sólido se desvanece en el aire. La experiencia de la modernidad. México: Siglo XXI Editores.

Bourdieu, P. (1999) Sobre el poder simbólico. En Intelectuales, política y poder. Buenos Aires: Eudeba.

Durkheim, É. (1997). Las reglas del método sociológico. México: FCE.

Giddens, A. (1993). Consecuencias de la modernidad. Madrid: Alianza.

Luhmann, N. (1997). Observaciones de la modernidad. Racionalidad y contingencia en la sociedad moderna. Barcelona: Paidós.

Marramao, G. (1998). Cielo y tierra. Una genealogía de la secularización. Barcelona: Paidós.

- (2006). Pasaje a Occidente. Filosofía y globalización. Buenos Aires: Katz.

Marx, K. (1987). Miseria de la filosofía. México: Siglo XXI Editores.

- (1989). Introducción general a la crítica de la economía política/1857. México: Siglo XXI Editores.

- (2001). Manuscritos de economía y filosofía. Madrid: Alianza.

- (2014). Antología. Buenos Aires: Siglo XXI Editores.

Marx, K. y Engels, F. (1974). Obras escogidas (Tomo I). Moscú: Progreso.

- (2013). Escritos sobre literatura. Buenos Aires: Colihue.

Rinesi, E. (2013). Muñecas rusas. Tres lecciones sobre la república, el pueblo y la necesaria falla de todas las cosas. Buenos Aires: Las Cuarenta.

Sazbón, J. (2002). El fantasma, el oro, el topo. En Historia y representación. Bernal: Universidad Nacional de Quilmes.

Vedda, M. (2013). Introducción. En Marx, K. y Engels, F. Escritos sobre literatura. Buenos Aires: Colihue.

Weber, M. (1979a). Introducción a La ética protestante y el espíritu del capitalismo. Barcelona: Península.

- (1979b). La política como vocación. EnElpolítico yel científico. Madrid: Alianza. (1980). La ciencia como profesión. En Ciencia y política. Buenos Aires: CEAL. (1998). Ensayos sobre sociología de la religión (Tomo I). Madrid: Taurus. (2003). La ética protestante y el espíritu del capitalismo. México: FCE. 